\title{
Improving the acquisition of English language competencies with international workgroups of university finance students
}

\section{Tascón, María T. ${ }^{\text {; }}$; Castro, Paula and Castaño, Francisco J. ${ }^{\mathbf{a}}$}

${ }^{\mathrm{a} D e p a r t m e n t ~ o f ~ B u s i n e s s ~ M a n a g e m e n t ~ a n d ~ E c o n o m y, ~ U n i v e r s i t y ~ o f ~ L e o ́ n, ~ S p a i n . ~}$

\begin{abstract}
This paper discusses a teaching innovation project that integrates technological communication advances with the small group methodology to improve the English competency of university students of finance. This is a fundamental competency for studies in finance considering the increasingly international framework of financial business and the increasingly required mobility of human resources in all types of financial careers. This methodology requires the cooperation of a foreign university to help students understand the practical implications of using English when applying the theoretical concepts and methodologies studied in class in an international professional setting. As a first approach, we implement and assess the implementation of this methodology and its impact on students' learning process in an elective module offered in an official degree in finance in Spain.
\end{abstract}

Keywords: International small working groups; linguistic competences; finance; university learning. 


\section{Introduction}

Finance is increasingly conducted in a global environment, in terms of not only financial markets but also corporate finance. It is therefore essential that graduates in finance have an international orientation and acquire the knowledge and skills to operate effectively within their financial careers. This means, among other things, that graduates are required to know the international language or lingua franca used by financial professionals - independently of their origin and country - which is English.

The Spanish National Institute of Education Assessment (2012) recognizes that nowadays appropriate training in languages, such as English, is essential for students that will face a global labor market requiring communication in contexts such as commercial, industry, tourism, and international relations. In financial careers, the new global environment indicates an increasing need for financial managers to collaborate in international expansion projects. This may be within a multinational firm or within a national one in the process of expanding its market through different agreements and contracts with foreign customers, or expanding its range of suppliers to an international extent. The globalization of financial markets compels financial advisors and personal financial consultants to use English as a professional language. In fact, they use English terms even when talking about professional matters in their mother tongue. Furthermore, the supranational standards and regulation of the banking and insurance industries (i.e., capital standards, solvency, financial stability), as well as the international integration of financial services firms, emphasize the need for training in English not only for professionals such as traders, dealers, or banking and insurance managers but also for the required higher number of experts in finance across all type of public and private international economic and financial governmental and nongovernmental institutions and organizations.

The significant challenges faced when working in international environments are not only concerned with communicating through a different language itself, or with the well-known problem of managing to conduct business with people from affiliated or third party firms with differing cultures. Additionally, as Sheppard et al. (2003) stated, some difficulties are caused by working through "virtual teams," which comprise physically separated individuals or groups that are connected by various information and communication technology tools.

In this paper, we explore how some contributions made by research or academic works in the distant areas of applied linguistics (learning of foreign languages, specifically), teaching methodology (small group learning), and information and communications technology (ICT) (e.g., groupware as defined by Whatley, 2006) can be used for the better acquisition of English language competency in the area of finance for university students. In the following paragraphs, we discuss how advances in these areas can be used to implement an 
effective program in which students from different universities and countries collaborate to work in groups.

This work is organized as follows. After the introduction, we discuss the selected methodology to effectively improve the acquisition of the financial English competence, that is, the international teamwork, for which the use of ICT is required. The third section explains our research project. Finally, we highlight the main conclusions of the work along with the limitations.

\section{Theoretical Framework}

The conceptual foundation for this innovation project relies on previous developments in three main areas of knowledge: the improvement of English competence for non-native English speakers, the usefulness of small working groups as a learning methodology, and the uses of ICT and related knowledge within the education context. Thus, the learning process is modified to include a complex new methodology to reduce or eliminate some deficiencies previously detected in students' acquisition of financial English competency, such as those related to the effective use of a foreign language in a professional international context.

\subsection{English competence}

The European Qualifications Framework (EQF), developed within the "Education and Training 2010" work program of the European Commission, includes communication in a foreign language among the key competences for lifelong learning, in addition to others such as basic competences in science and technology, digital competence, learning to learn, interpersonal and civic competences, and cultural expression (Martyniuk, 2006). It is a common European framework to be taken as a reference for the key competences for communication in a foreign language. The $\mathrm{EQF}$ mentions the following descriptors.

- "Knowledge of vocabulary and functional grammar and an awareness of the main types of verbal interaction and registers of language; of societal conventions, and the cultural aspect and variability of languages;

- Skills to understand spoken messages, to initiate, sustain and conclude conversations and to read and understand texts appropriate to the individual's needs; to be able to use aids appropriately, and learn languages also informally as part of lifelong learning; 
- A positive attitude involving the appreciation of cultural differences and diversity, and an interest and curiosity in languages and intercultural communication."

Barner-Rasmussen et al. (2014) specify that language skills can refer to the language of a subunit in a country, such as a corporate language, a professional or functional language, a regional lingua franca, and/or "company speak." For example, the language skills under study in our case are those of the professional financial English concerned with business valuation.

\subsection{English in students' financial career}

As mentioned previously, in today's global financial business realities, financial professionals have to face and overcome some language boundaries. Barner-Rasmussen et al. (2014) gather a list of advantages from the literature for professionals with relevant language skills. They tend to become "language nodes" with better-than-average access to information. This enables them to act as "language mediators," "bridge builders," or "bridge individuals," taking on a range of intermediary roles (e.g., as gatekeepers, liaisons, translators, and intermediaries for colleagues with more limited language skills). In turn, these roles help them build networks and formal or informal positions of power. Consequently, English skills turn out to be a strategic part of future financial professionals' training. This is a powerful reason to motivate to learn as well as to pay attention to the learning dynamics of the English language (Spanish National Institute of Education Assessment, 2012) in schools and universities.

\subsection{The role of ICT to facilitate international learning-teaching experiences in university}

ICT has opened a universe of possibilities within the learning-teaching environment. When communication and groupware possibilities are included as teaching-learning supporting tools in combination with new techniques, such as learning-by-doing and case studies, students can acquire relevant skills and competencies (Whatley, 2006; González and Jimenez, 2014). Furthermore, the internet contributes to removing time and space barriers and allows students to move with more flexibility through cyberspace (Gonzalez, Gallardo, and Jimenez, 2014). An interesting derivation of this possibility is that students can attend classes at distant universities as online participants when virtual learning is implemented in that specific university. A more interesting possibility for our purpose is that professors and students can collaborate on common teaching-learning experiences from different universities, located even in distant countries. An increasing variety of tools is available to 
be used, such as platforms to share or exchange information and to work in groups with simultaneous access, chats, wikis, social networks, e-mails, and WhatsApp.

The University of Leon is involved in a strategic plan to internationalize professors, students, and degrees, by promoting diverse initiatives to raise the level of professors' and students' foreign languages. Our project is developed within this framework, as the main goal is improving the financial English competency of the students of an elective module included in an official degree. The possibility of working with foreign students (enrolled in a different university) collaborating on a common project but taking part in their own module in their own institution, and with their own professor codirecting the project, offers a number of advantages. The international content of the project, necessary to take advantage of the knowledge of the two (or more) countries involved, enhances the international elements of the module (and the degree) program. Additionally, this is an experience of internationalization for local students and professors, who may not have the opportunity to go abroad. The practice of English as the only possible language for communication may be seen as an advantage by most participants in that it may provide motivation for improving English competency, while it may be seen as a disadvantage by a lower group of low-level English speakers.

\subsection{The use of international working groups}

Learning in small groups is the most appropriate way to expose students to a comprehensive language learning experience. In fact, small group work has been increasingly used to developing students' communicative competence in English as a foreign language (Fushino, 2010). The reasons are that in small groups students interact with each other in natural ways (informal contexts), which is likely to develop their communicative competence in English (Fushino, 2010), but they also have to negotiate meanings, use technical terms, present ideas, and persuade (Jacques, 1991). Furthermore, the impossibility of communicating in their mother tongue with a part of the group takes the students into a linguistic immersion experience in a real-life academic activity. That immersion produces significantly higher performance in communication skills for these students than for those other students not involved in the same way in these types of activities (Spanish National Institute of Education Assessment, 2012).

However, this teaching-learning methodology does not lack some disadvantages. Students may work actively in groups, and their participation (willingness to communicate) will be conditioned by nonlinguistic and noncognitive contextual factors such as classroom layout, students' interpretation of their tasks, and peer relationships (Fushino, 2010). When a second language is used, the limitations of the small group learning methodology concerning communication are exacerbated. Thus, freeloading, distraction from the task, 
and vocal dominance by a minority or just one person (Gunn, 2007) may hinder the learning process. Additionally, an international group includes different cultures, and the effect of these differences is stressed in distance learning (Gunn, 2007). Thus, social interaction to get a sense of the community of learning is undoubtedly more difficult in computer-supported collaborative learning settings than in face-to-face settings (Kreijns, Kirschner, and Jochems, 2003).

Fushino (2010) finds evidence that active interaction between students depends on the students' balance between communication confidence and communication apprehension. Some advisable actions to reduce apprehension are: providing teambuilding activities with which group members can develop bonds, facilitating a supportive atmosphere, and avoiding teaching and peers' critical attitudes. Other actions are recommended to help students gain communication confidence. For example, assigning success-oriented, doable tasks with clear instructions, demonstrations, and easy-to-follow steps (Jacobs, 2007).

\section{Research Project}

Our project uses a case study methodology where the students are placed into international working groups, in a virtual learning environment.

\subsection{Description of the research design}

We formed small groups made up of four members (occasionally five, when the total number of students was not enough to form a new group): two Spanish members, and two Belgian ones. Considering that the English level of the Spanish students was heterogeneous, and poor in some cases, every group was formed with at least one student with a minimum level of English. The supportive intention was highlighted to reduce communication apprehension in regard to contact with the foreign members of the group. Thus, apart from the innovative international feature, the education method can be defined as tutor-oriented small group learning, considering the organization of the work (Gunn, 2007), but also as problem-based learning, if we focus on the nature of the tasks realized.

During the second semester of 2014-15, we implemented a case methodology to be performed by international small groups to improve the English teaching-learning experience within the Financial Firms Valuation module of the Finance Degree at the University of León. This is an elective course, in which the students obtain a deeper knowledge and higher level of practical application in business valuation after they have studied a previous mandatory module on the subject. This is a proper module to be taught partly in English, as the Spanish students acquired basic knowledge on concepts and 
methodologies in the previous mandatory module during the first semester. Therefore, they are in a good condition to conduct an initial review of these concepts and methodologies in English at the beginning of the second semester. Thus, we planned to teach theoretical sessions in English, practical ones in Spanish, and tutorial practical ones in English (Spanish on demand).

To motivate students to use English during the practical part of the module, we decided to form international work groups in which some of the students were not Spanish speakers. They need not be native English speakers to provide both parts of each group with the same incentive to improve their foreign language skills to communicate with others. In the case of our students, the degree program is almost completely taught in Spanish, except for two elective modules of English and the elective module on business valuation, which is half taught in English. The students' level of English is heterogeneous, and sometimes poor, especially their listening skills, in line with the English level of Spanish students, as indicated by international level tests (European Commission, 2012; National Institute of Education Assessment, 2012). To cope with this drawback, we included at least one student with higher-level language proficiency from each country to facilitate communication with the part of the group from the other country.

E-learning devices are necessary for communication (a platform, social networks, etc.). Written communication favors the understanding of Spanish students, because listeningspeaking skills are not necessary. The resolution of case studies by groups fosters teamwork and communication skills in English between both parts of the group from different nationalities.

An e-learning environment is necessary to integrate students and professors from both universities into the same activity. From the initial contact between the professors to decide to collaborate, lots of information has to be exchanged until the final assessment of the activity, and all messages and documents sent from a member of one university to a member of the other must be in English, forcing all the participants to develop linguistic competences. Thus, for the students, it is necessary to read academic English texts, follow the lectures' explanations on the theoretical and practical aspects of the work, think about the content of the written work to be performed, write messages to the other part of the group and read the ones received from them, write the part of the written essay decided by agreement, and critically review the work written by the other members to properly integrate every part in teamwork. For the professors, it is necessary to establish contact and decide the content and conditions of collaboration to fulfill the module requirements for each university. It is likely that the modules have remarkable differences in content, objectives, competencies to be obtained, and ways of assessment, as well as schedule, vacation periods, and beginning and ending dates. Additionally, the professors have to prepare the texts of the case study and the material to explain the theoretical concepts and 
practical methodologies to be used (excel pages, real case practical examples, etc.). During all these required communication activities, both formal academic and colloquial/informal English must be used by students and professors.

Therefore, the case study activity is going to be used to attain two different groups of competences: (1) those related to the acquisition of knowledge (theoretical concepts and practical methodologies) and its use to solve real-data problems in finance, and (2) those related to the use of English in a professional teamwork scenario.

The case study concerns the financial aspects of the international expansion of a firm. Material is provided to the students, and each lecturer conducts a lesson (through video conference to the students in the other country). During tutorial hours, the professors help students understand the case and obtain information from the internet to solve the case and develop the computing and written solution of the case. The students are given some questions, some deadlines to finish relevant parts of the work, and a final deadline to deliver the whole solution of the case.

The written material with the case is provided to the students through the university virtual platform (for example, Moodle). The members of the groups can examine a part of or the whole information as many times as they need to develop the quantitative proposal of the group and to write the essay to answer the questions. Several partial deadlines are established for students to send specific portions of the work to the part of the group in the other country. During the tutorial practical sessions in the computer room, the professors help the students with theoretical, methodological, and linguistic doubts before sending the required portions of the work to the part of the group in the other country. The material elaborated by each part of the group (they have parallel assignments) must be reviewed by the other part to make suggestions to improve it and also to integrate all the parts as a unique homogeneous written work. This way, the students will have the opportunity to value the partial solution given by the other half of the group and to decide whether their own answers fit with it and have a similar level of quality academically as well as grammatically. Finally, both the excel page and written essay are sent via the virtual platform to the corresponding professor for assessment. Further, the students are required to keep an individual diary of the whole practice to serve as an indication of their participation and as a way for every student to express his/her opinion and assessment on the development of the teamwork. The professor can assess the individual implications and individual level of English of each student. 
Phase 1: Establish an agreement with a professor in the same field of knowledge with similar didactic interests in a foreign university. As the first approach, English should be the second language in both universities. None of the students should be a native English speaker.

Phase 2: Preparation of the case study material.

Phase 3: Agreement on the agenda and conditions of participation for lecturers and students.

Phase 4: Formation of international small groups and interconnection through ICT tools.

Phase 5: Working in groups with tutorial assistance from the professor/lecturer.

Phase 6: Assessment of the students' academic and linguistic competencies in both the group essay on the practical case and the individual diary on the practice.

\subsection{Students' perception of changes in their English competency}

To evaluate the students' perceptions on the implementation of the methodology, we included several multiple-choice questions in a questionnaire posed at the end of the semester. Most of the questions allow only one answer to be chosen, and a few are flexible to allow more than one answer to be chosen. The questionnaire was distributed through the virtual platform of the university, thus avoiding transcribing errors. The number of students following the course was 17 from each university, but these questions were posed only to Spanish students, which are the group under study in our project. 
Table 1. Questionnaire (only questions referring to the project are included)

\begin{tabular}{|c|c|c|}
\hline $\begin{array}{l}\text { 1.- Has it been difficult to follow the } \\
\text { classes in English? }\end{array}$ & $\begin{array}{l}\text { a) Quite a lot } \\
\text { b) No, or Hardly } \\
\text { c) It became less difficult as the course advanced }\end{array}$ & $\begin{array}{l}35 \% \\
47 \% \\
18 \%\end{array}$ \\
\hline $\begin{array}{l}\text { 2.- Have the theoretical classes in } \\
\text { English (with written documents in } \\
\text { English) helped you to improve your } \\
\text { knowledge of technical vocabulary? }\end{array}$ & $\begin{array}{l}\text { a) Quite a lot } \\
\text { b) No, or Hardly } \\
\text { c) Do not know/No comment }\end{array}$ & $\begin{array}{l}65 \% \\
29 \% \\
6 \%\end{array}$ \\
\hline $\begin{array}{l}\text { 3.- Have the theoretical classes in } \\
\text { English (with written documents in } \\
\text { English) helped you to improve your } \\
\text { skills in reading, writing and speaking } \\
\text { in English on the module contents? }\end{array}$ & $\begin{array}{l}\text { a) Quite a lot } \\
\text { b) No, or Hardly } \\
\text { c) Do not know/No comment }\end{array}$ & $\begin{array}{l}65 \% \\
29 \% \\
6 \%\end{array}$ \\
\hline $\begin{array}{l}\text { 4.- What was your experience of } \\
\text { collaboration with a foreign university } \\
\text { and of taking part in an international } \\
\text { group like? }\end{array}$ & $\begin{array}{l}\text { a) I liked it as a new experience; I have seen } \\
\text { different ways of working and viewpoints } \\
\text { b) I did not like it. Organizing the work was } \\
\text { difficult because of the different focus } \\
\text { c) It forced me to use English in practice and that } \\
\text { made me improve } \\
\text { d) It forced me to use English in practice and that } \\
\text { was difficult and stressful }\end{array}$ & $\begin{array}{l}47 \% \\
35 \%\end{array}$ \\
\hline $\begin{array}{l}\text { 5.- Should this type of practice be } \\
\text { maintained as a part of the module? }\end{array}$ & $\begin{array}{l}\text { a) Yes } \\
\text { b) No } \\
\text { c) Do not know/No comment }\end{array}$ & $\begin{array}{l}76 \% \\
6 \% \\
18 \%\end{array}$ \\
\hline
\end{tabular}

Looking at the percentage of answers in Table 1, we can see the poor heterogeneous English level of the students (35\%) and their difficulties with following classes (though the main professor was not an English native speaker, but a Spanish one with a C1 level). The first positive result is the perceived improvement in the ability to follow classes by $18 \%$ as the course advanced. The same proportion of students (65\%) felt an improvement in both technical vocabulary and communication skills (reading, writing, and speaking). Concerning the integration in international small groups, the same proportion of students with difficulties in following the classes $(35 \%)$ found the organization of work difficult because of the different focuses. Nevertheless, only $12 \%$ of them believe that being forced to use English in practice was difficult and stressful while $45 \%$ of students think that being forced to use English in practice made them improve. Finally, 76\% of participants think that this type of practice should be maintained, which we interpret as a positive global perception. 


\section{Conclusions, Limitations and Further Research}

We have implemented an innovative methodology to help students improve their financial English competency: international small working groups. The proposed methodology benefits from some advantages for foreign language learning using small working groups, which can be summed up as interaction among students to communicate technical knowledge in an informal context. The international origin of the group members forces linguistic immersion in a real-life academic activity, which allows $45 \%$ of students to improve.

At the same time, the use of small groups has some limitations, as students cannot be forced to participate at a specific expected high level of communication. This limitation is exacerbated by talking in English and by the use of ICT communication tools instead of face-to-face communication. To cope with these limitations, we have been cautious in ensuring that at least one of each group of participants has a minimum level of English and that every international session is tutored by two professors jointly to resolve any possible doubts faster or avoid any communication pitfall. Considering the lower level of Spanish students in listening and talking skills, written communication through ICT tools turned to be an advantage, in contrast to the listening-speaking alternative of face-to-face communication. By contrast, differences in teaching focus, learning culture, degree programs, holidays, and festivities by country turned to be the most salient obstacles to the success of the practical application of the methodology.

This study is the first approach to the use of this kind of teaching-learning methodology. Therefore, despite the promising perceived improvements in the financial English competencies of the students, the difficulties with coordinating a practice point to the need to pay attention to the temporal coordination of the module contents by considering calendar differences. This type of practice is time consuming for professors and cannot be implemented in big groups, but it would be interesting to apply the practice to a group of students large enough to differentiate results by different levels of English.

\section{References}

Barner-Rasmussen, W., Ehrnrooth, M., Koveshnikov, A., and Mäkelä, K. (2014). Cultural and language skills as resources for boundary spanning within the MNC. Journal of International Business Studies, 45, 886-905.

European Commission (2012). First European survey on languages competences. Report on Education and Training. June. Available at http://ec.europa.eu/languages/library/studies/executive-summary-eslc_en.pdf 
Fushino, K. (2010). Causal relationships between communication confidence, beliefs about group work, and willingness to communicate in foreign language group work. Tesol Quarterly, 44(4), 700-724.

González, I., Gallardo, E. \& Jiménez, A.I. (2014). Using learning methodologies and resources in the development of critical thinking competency: An exploratory study in a virtual learning environment. Computers in Human Behavior, 30, 1-8.

González, I. \& Jiménez, A.I. (2014). Using films to develop the critical thinking competence of the students at the Open University of Catalonia (UOC): Testing an audiovisual case methodology in a distance e-learning environment. Computers in Human Behavior, 30, 739-744.

Gunn, V. (2007). Approaches to Small Group Learning and Teaching. Working Paper Learning and Teaching Centre. University of Glasgow, 1-23.

Jacques, D. (1991). Learning in Groups, London: Kogan Page.

Kreijns, K., Kirschner, P.A., \& Jochems, W. (2003). Identifying the pitfalls for social interaction in computer-supported collaborative learning environments: a review of the research. Computers in Human Behavior, 19(3), 335-353.

Martyniuk, W. (2006). European Frameworks of Reference for Language Competences. Preliminary study. Languages of Education. Intergovernmental Conference: Languages of Schooling: towards a Framework for Europe, Strasbourg, 16-18 October, organized by the Language Policy Division of the Council of Europe.

National Institute of Education Assessment - Instituto Nacional de Evaluación Educativa (2012). Estudio europeo de competencia lingüística EECL. Volumen II: análisis de expertos. Secretaría técnica. Subdirección General de Documentación y Publicaciones. Ministerio de Educación, Cultura y Deporte.

Sheppard, K., Dominick, P., and Aronson, Z. (2003). Enhancement of the Global Perspective for Engineering Students by Providing an International Experience. Proceedings. Engineering Conferences International. Available at ECI Digital Archives. http://dc.engconntl.org/enhancement/27

Whatley, J. (2006). Student teamwork: Developing virtual support for team projects. Interactive Technology and Smart Education, 3(2), 157-165. 